\title{
AVALIAÇÃO DA EFICIÊNCIA DO MÉTODO SODIS COM E SEM O USO DE CONCENTRADOR SOLAR PARA DESINFECÇÃO DE ÁGUA DA CISTERNA LOCALIZADA NA ZONA RURAL DE ALAGOA NOVA - PB
}

\author{
C. S. de OLIVEIRA ${ }^{1}$, Dr ${ }^{\mathrm{a}}$. N. C. SOUZA ${ }^{1}, \operatorname{Dr}^{\mathrm{a}}$. M. R. LUIZ ${ }^{1}$ \\ ${ }^{1}$ Universidade Estadual da Paraíba, Departamento de Engenharia Sanitária e Ambiental \\ E-mail para contato: marciarluiz@yahoo.com.br
}

\begin{abstract}
RESUMO - A ausência de um sistema de tratamento e distribuição de água nas zonas rurais das cidades faz com que se busquem fontes alternativas de água para o consumo humano. Objetivando melhorar a qualidade microbiológica da água, o método SODIS pode ser utilizado. Este é um método simples e fácil de ser aplicado, eliminando microrganismos utilizando radiação solar, com uso de garrafas PET transparentes. Este trabalho propôs o comparativo entre as eficiências e o tempo de inativação microbiológica das amostras da água que foram submetidas à desinfecção com e sem o uso do concentrador de raios solares. Foi possível observar que nas amostras que não fizeram uso do concentrador solar houve a diminuição da concentração microbiana na água, porém o tempo de 6 horas não foi suficiente para eliminar completamente os microrganismos contaminantes. Já as amostras que utilizaram o concentrador solar foram eliminados todos os termotolerantes e coliformes totais, em 4 horas, comprovando a eficiência do mesmo.
\end{abstract}

\section{INTRODUÇÃO}

A importância do serviço de abastecimento de água público é grandemente reconhecida no sentido de promover a prevenção de doenças de veiculação hídrica e reduzir o índice de mortalidade relacionado ao consumo de água não potável. Segundo a ONU (2013), estima-se que um 1,6 bilhão de pessoas não tem acesso a um abastecimento de água suficiente, principalmente as que residem na zona rural das cidades. Realidade responsável pela morte de 17 mil crianças diariamente pelo mundo.

A implantação de Estações de Tratamento de Água e de sistemas de distribuição que atendam completamente a população é onerosa e requer profissionais capacitados para operá-las. Por esse motivo, uma parcela da população não é atendida por esse serviço, levando à busca de outras fontes alternativas de abastecimento de água, estas incluem poços, nascentes e a coleta de águas pluviais. Devido à ausência de tratamento da água adequado, alternativas são adotadas.

Para a desinfecção com o objetivo de produzir água para consumo humano deve garantir que seja isenta da presença de micro-organismos patogênicos e indicadores, cuja inativação é feita por meio de agentes físicos e/ou químicos (LIBÂNIO, 2008). Os agentes químicos são 


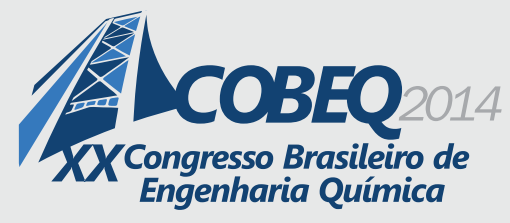

compostos com potencial de oxidação, incluindo o cloro, dióxido de cloro e ozônio, são os mais usados na desinfecção da água. E os agentes físicos que apresentam ação referenciada à energia de radiação, destacando-se a fervura, a radiação ultravioleta e a radiação solar.

Uma opção para desinfecção utilizando energia solar é o método conhecido como SODIS ou Desinfecção Solar da Água (solar water disinfection), que usa o mecanismo de eliminação bacteriana pela incidência de raios solares. Segundo Wegelin (1994), com o uso desse método ocorre a inativação dos seguintes micro-organismos: Escherichia coli, Streptococcus faecalis, Salmonella, Bacteriófago f2, Rotavírus, Encefalomiocardite e Oocistos de cryptosporidium SP.

Além de ser uma alternativa simples e de baixo custo, a radiação solar é uma fonte limpa, renovável e abundante de energia, principalmente em áreas com temperaturas elevadas, podendo ser aproveitada em diferentes níveis em todo o mundo. Dependendo da localização geográfica, quanto mais perto do equador, mais energia solar pode ser potencialmente captada.

A luz solar emite as radiações solar infravermelha e ultravioleta, provocando a inativação de micro-organismos, portanto eficaz na desinfecção da água para consumo. A radiação infravermelha é responsável pela desinfecção através da elevação da temperatura da água, entre $60^{\circ}$ e $70^{\circ} \mathrm{C}$, conhecido como SOPAS (solar pasteurization). Tendo como vantagem a total eliminação dos micro-organismos e evitando seu recrescimento (RODRIGUES, 2011). Já a radiação ultravioleta penetra na parede celular e a energia dos fótons da radiação é absorvida pelas proteínas e pelo DNA da célula danificando a estrutura proteica e ocasionando uma alteração química no DNA. Desta forma, quando o DNA sofre divisão celular, esta não pode realizar metabolização e reproduzir-se, o que não podem causar doenças (MELÉNDEZ, 2011).

Desinfecção Solar da Água ou SODIS (solar water disinfection) foi estudada inicialmente por Acra et al. (1984 apud SOUZA, 2009) e aprimorada pelo instituto EAWAG, na Suíça e consiste em remover agentes patógenos da água armazenando-a em garrafas do tipo PET (polietileno tereftalato) transparentes e deixando-as expostas à luz solar durante o tempo de 6 horas, conforme descrito na Figura 1, aquecendo a água a uma temperatura em torno de $50^{\circ} \mathrm{C}$, tendo eficiência de 100\% na inativação de Coliformes totais e E.coli (PATERNIANI, 2005).

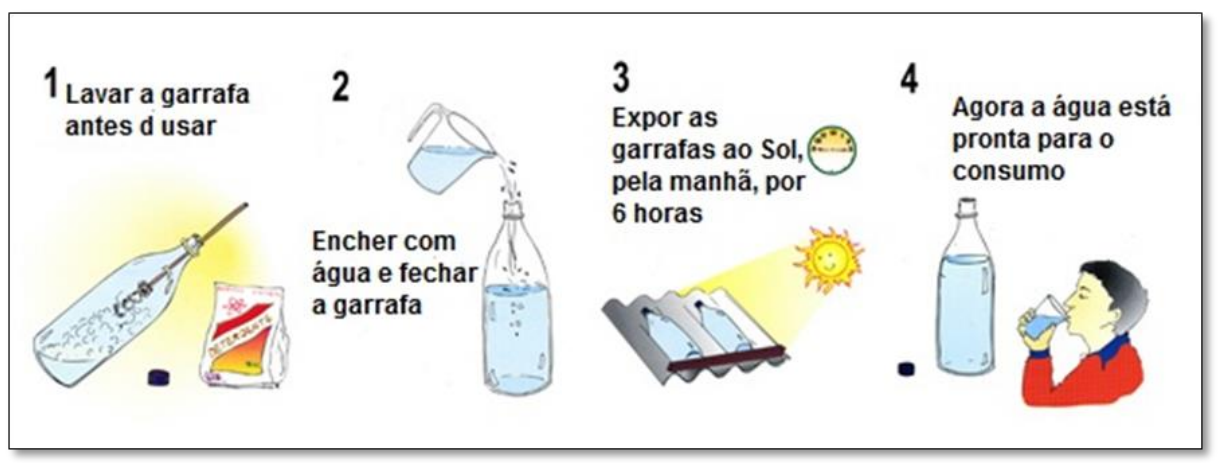

Figura 1: Método de desinfecção SODIS. Fonte: SODIS (2013). 
Devido o PET possuir menos aditivos que outros plásticos ele é preferido pelo menor potencial de contaminação da água. As garrafas PET possuem estabilizantes para conter a degradação devido à exposição aos raios UV, não sofrendo alterações nas características químicas quando testado em laboratório pelo período de 1100 horas de exposição (SILVA, 2004). A garrafa pode ser pintada de preto o que é justiçado pelo princípio da radiação do corpo negro, a qual toda a radiação incidida não é refletida e sim, totalmente absorvida, contribuindo para o aumento da temperatura do sistema (CARRON e GUIMARÃES, 2006).

De acordo com SODIS (2013), 6 horas de exposição são necessárias para inativar os micro-organismos presentes na água. Visando reduzir o tempo de exposição da água e aumentar a eficiência do método, evitando o recrescimento bacteriano, o Instituto Mexicano de Tecnologia da Água, desenvolveu um concentrador de raios solares, feito de madeira e revestido de papel alumínio que tem o objetivo de reduzir o tempo de exposição de 6 para 4 horas.

Este é um procedimento técnico e economicamente viável para o tratamento de água em comunidades principalmente rurais e pobres que não têm acesso à água potável, tendo como referência de custo US $\$ 3,00$ por ano para uma residência de cinco pessoas utilizando garrafas PET. Essas características fazem com que o sistema tenha aceitação de $84 \%$ dos usuários de países em desenvolvimento, como Colômbia, Bolívia, Indonésia, Tailândia e China (SILVA, 2004) e seja recomendado pela ONU como um método viável para o tratamento de água doméstico e armazenamento seguro. Estima-se que mais de 5 milhões de pessoas tratam sua água desta forma, em 15 países da África, Ásia e América Latina (SODIS, 2013).

Com todo esse respaldo pretende-se com este estudo fazer uma avaliação da eficiência do método SODIS com e sem o uso de um concentrador, modificado, de raios solares, fazendo um comparativo do tempo de exposição e percentual de micro-organismos inativados em uma cisterna localizada na zona rural de Alagoa Nova - PB.

\section{METODOLOGIA}

\subsection{Local de Estudo e Materiais Utilizados}

As amostras de água utilizadas para realização das análises foram coletadas de uma cisterna localizada no povoado São Tomé de Cima, no Município de Alagoa Nova, Paraíba. O experimento foi realizado na cidade de Campina Grande, Universidade Estadual da Paraíba UEPB, no Centro de Ciências e Tecnologia - CCT. As análises foram executadas no laboratório de alimentos, Núcleo de Pesquisa e Extensão em Alimentos - NUPEA.

Para o armazenamento das amostras de água, expostas ao sol, foram utilizadas garrafas PET de 2 litros na cor transparente, sendo metade delas lixadas e pintadas de tinta na cor preto fosco, totalizando sete garrafas, conforme a Figura 2. A parte não pintada da garrafa ficou exposta à radiação solar. 


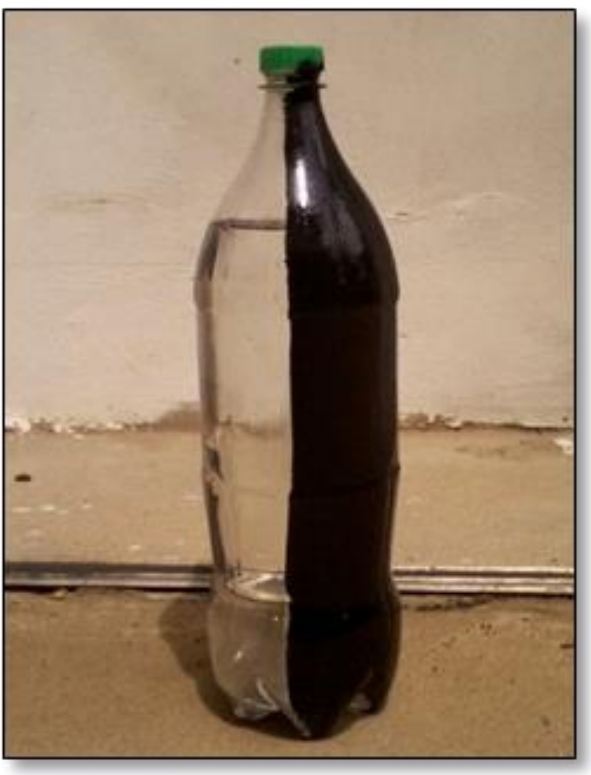

Figura 2 - Garrafa PET transparente pintada de preto.

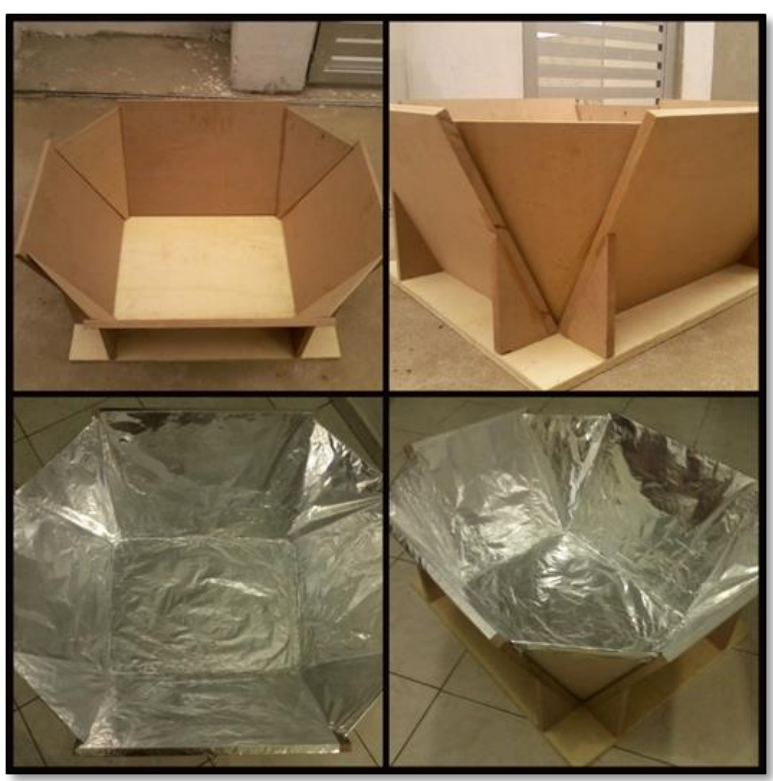

Figura 3 - Concentrador solar.

O concentrador de raios solares, desenvolvido pelo Instituto Mexicano de Tecnologia da Água foi utilizado como princípio para confecção do concentrador solar em estudo, construído de madeira e revestido com papel alumínio. Na Figura 3 é apresentado o concentrador solar utilizado nos experimentos. Houve uma alteração na sua estrutura, fechando completamente as arestas laterais, ficando apenas a parte superior aberta para receber a radiação solar. As dimensões do concentrador foram obtidas de acordo com Silva (2004). Na Tabela 1 são apresentadas as medidas adaptadas.

Tabela 1 - Medidas adaptadas do concentrador solar

\begin{tabular}{|l|l|}
\hline Medida da peca $(\mathbf{c m})$ & Quantidade \\
\hline Base $=67,66 \times 55$ & 1 unidade \\
\hline Aletas $=47,66 \times 35$ & 2 unidades \\
\hline Aletas $=35 \times 35$ & 2 unidades \\
\hline Suportes triangulares $=8,5 \times 15 \times 17,5$ & 8 unidades \\
\hline Arestas $=22 \times 32 \times 32$ & 4 unidades \\
\hline
\end{tabular}

\subsection{Experimento}

As amostras de água para ser submetida à desinfecção foram coletadas de uma cisterna no povoado São Tomé de Cima, no Município de Alagoa Nova - PB, no período da manhã, no dia 10 de fevereiro de 2014 às 8 horas, transportadas sob refrigeração até a UEPB para a execução 
do experimento. A água é proveniente da chuva que cai sobre o telhado da casa, escoa pela calha e enche a cisterna.

A água coletada foi armazenada em garrafas PET de 2 litros, previamente lavadas. As garrafas foram expostas à radiação solar às 9 horas $\left(T_{0}\right)$, três delas usando o concentrador solar e três sem o uso do concentrador e um como padrão. Apesar do recomendado por Silva (2004) fosse que o concentrador ficasse inclinado $8 \mathrm{~cm}$, optou-se pela não inclinação do mesmo, para não alterar a posição do concentrador, evitando que as aletas fizessem sombra sobre as garrafas, como apresentado na Figura 4 (a), sem o concentrador e (b) com o concentrador.

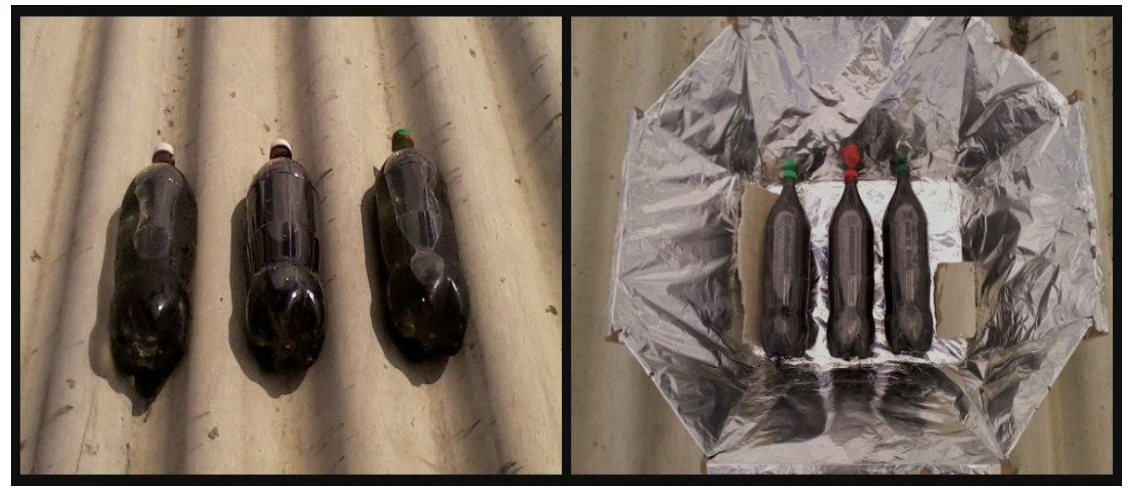
(a) Sem o concentrador solar
(b) Com o concentrador solar

Figura 4 - Garrafas expostas à radiação solar com e sem o uso do concentrador solar.

Após o tempo de amostragem de duas horas, às 11 horas $\left(T_{2}\right)$, duas garrafas foram recolhidas, uma exposta ao sol diretamente e outra que utilizou o concentrador solar, as mesmas foram submetidas imediatamente à análise microbiológica para a quantificação de Coliformes totais e termotolerantes. $\mathrm{O}$ mesmo procedimento foi repetido às 13 horas $\left(T_{4}\right)$ e às 15 horas $\left(T_{6}\right)$.

As análises foram realizadas de acordo com o "Standard Methods for the Examination of Water and Wastewater" (APHA; AWWA; WEF, 2005). O método usado para a determinação de Coliformes totais e termotolerantes foi o de tubos múltiplos.

\subsection{Cálculo para a Eficiência de Inativação de Micro-Organismos}

Para o cálculo da eficiência de inativação de micro-organismos utiliza-se o Número Mais Provável final e inicial das amostras analisadas, como pode ser visto na Equação 1.

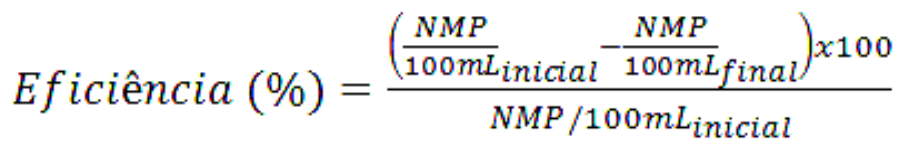

Onde:

NMP = Número Mais Provável 


\section{RESULTADOS E DISCUSSÃO}

O experimento foi realizado na cidade de Campina Grande, que está a $551 \mathrm{~m}$ em relação ao nível do mar e latitude de $7^{\circ} 13^{\prime} 51^{\prime \prime}$ ao sul da linha do equador. A latitude influencia de acordo com a forma em que os raios solares atingem a Terra. Onde devido ao formato esférico da Terra, eles atuam com maior insolação no equador. Então a temperatura diminui com o aumento da latitude. Já a altitude exerce grande influência na temperatura, quanto maior a altitude, o ar se torna mais rarefeito e ocorre menor irradiação, causando menores temperaturas. $\mathrm{O}$ que pode influenciar positiva ou negativamente este estudo. A Tabela 2 apresenta as condições meteorológicas no dia do experimento.

Tabela 2 - Condições meteorológicas de Campina Grande no dia do experimento

\begin{tabular}{|c|c|c|c|c|c|c|c|c|c|c|}
\hline \multicolumn{10}{|c|}{ Dados Meteorológicos de Campina Grande no dia 10/02/2014 } \\
\hline Hora & Temperatura $\left({ }^{\circ} \mathrm{C}\right)$ & \multicolumn{3}{c|}{ Umidade $(\%)$} & \multicolumn{3}{c|}{ Pressão $(\mathrm{hPa})$} & Radiação(kJ/m $\left.{ }^{2}\right)$ \\
\hline & Inst. & Máx. & Mín. & Inst & Máx. & Mín & Inst. & Máx. & Mín. & \\
\hline To & 20,6 & 20,8 & 20,4 & 94 & 95 & 94 & 952 & 952 & 951,4 & 65,75 \\
\hline T2 & 23,5 & 23,9 & 22,3 & 78 & 91 & 76 & 952,9 & 952,9 & 952,6 & 1559 \\
\hline T4 & 26,7 & 27,1 & 25,1 & 62 & 68 & 61 & 952,5 & 953,1 & 952,5 & 2520 \\
\hline T6 & 29,2 & 30,3 & 27,7 & 49 & 57 & 47 & 951,3 & 951,8 & 951,3 & 2795 \\
\hline
\end{tabular}

Fonte: AESA (2014).

Com a Tabela 2 pode-se verificar que ocorrem o máximo de temperatura no último ponto de estudo, às 15 horas $\left(\mathrm{T}_{6}\right)$, com menor umidade relativa e maior radiação solar. Sendo estas condições mais adequadas para a realização do experimento.

Através da técnica dos tubos múltiplos tornou-se possível quantificar o número de coliformes totais e termotolerantes eliminados durante o processo, os valores encontrados podem ser verificados nas Tabelas 2 e 3 .

Tabela 2 - Número Mais Provável de Coliformes totais (NMP/100mL) contidos nas amostras após desinfecção pelo método SODIS

\begin{tabular}{|c|c|c|}
\hline & \multicolumn{2}{|c|}{ Coliformes Totais } \\
\hline & \multicolumn{2}{|c|}{ Combinação de Número mais provável por $100 \mathrm{~mL}$ positivos } \\
\hline Tempo (h) & Sem Concentrador & Com Concentrador \\
\hline 0 & $5-5-5 \quad 2400,0$ & $5-5-5 \quad 2400,0$ \\
\hline 2 & $5-5-4 \quad 1600,0$ & $5-5-4 \quad 1600,0$ \\
\hline 4 & $2-1-0$ & $0-0-0$ \\
\hline 6 & $2-0-0$ & $0-0-0$ \\
\hline
\end{tabular}

De acordo com a Tabela 2, pode-se verificar que para os tempos de amostragem de 4 e 6 horas todos os tubos contendo amostras que usaram o concentrador foram negativos para Coliformes totais. Já sem o uso do concentrador solar, o tempo de 4 horas não foi suficiente para 
eliminá-los totalmente. Nas 6 horas, verificou-se a redução da quantidade de micro-organismos presentes na amostra, mas não a sua eliminação completa, contradizendo Silva (2004), que indica que de 6 horas seria o suficiente para eliminar completamente bactérias do grupo coliforme. No tempo $T_{0}$, a densidade microbiológica foi superior a 1600 Coliformes totais / $100 \mathrm{~mL}$.

Tabela 3 - Número Mais Provável de Coliformes termotolerantes (NMP/100mL) contidos nas amostras após desinfecção pelo método SODIS

\begin{tabular}{|c|rr|rr|}
\hline \multirow{2}{*}{ Tempo (h) } & \multicolumn{4}{|c|}{ Coliformes termotolerantes } \\
\cline { 2 - 5 } & \multicolumn{3}{|c|}{ Combinação de Número mais provável por 100mL positivos } \\
\hline 0 & Sem Concentrador & \multicolumn{2}{c|}{ Com Concentrador } \\
\hline 2 & $5-5-5$ & 2400,0 & $5-5-5$ & 2400,0 \\
\hline 4 & $5-5-2$ & 540,0 & $5-5-2$ & 540,0 \\
\hline 6 & $2-0-0$ & 4,5 & $0-0-0$ & 0,0 \\
\hline
\end{tabular}

De acordo com a Tabela 3, pode-se verificar que para os tempos de amostragem de 4 e 6 horas todos os tubos contendo amostras que usaram o concentrador foram negativos para Coliformes termotolerantes. O comportamento sem o uso do concentrador solar para o tempo de 4 e 6 horas foi semelhante ao de Coliformes totais, não sendo suficiente para eliminá-los totalmente.

As eficiências da desinfecção do método SODIS com e sem o uso do concentrador solar foi realizadas utilizando a Equação (1) e os resultados podem ser verificados na Tabela 4.

Tabela 4 - Eficiência dos sistemas com e sem o concentrador solar para Coliformes totais e termotolerantes $(\mathrm{NMP} / 100 \mathrm{~mL})$

\begin{tabular}{|l|c|c|}
\hline \multirow{2}{*}{ Com concentrador } & \multicolumn{2}{|c|}{ Eficiência (\%) } \\
\cline { 2 - 3 } & Coliformes Totais & Coliformes termotolerantes \\
\hline Sem concentrador & 100,00 & 100,00 \\
\hline
\end{tabular}

Pode-se verificar, de acordo com a Tabela 4, que o uso do concentrador solar favorece a inativação de Coliformes totais e termotolerantes. O resultado atende a Portaria $N^{\circ} 2914 / 2011$ do Ministério da Saúde, que retrata o padrão microbiológico da água para consumo humano a ausência tanto de Coliformes totais quanto de termotolerantes, para $100 \mathrm{~mL}$ de amostras, o que foi obtido após 4 horas de exposição das amostras com o concentrador solar.

\section{CONCLUSÃO}

Foram realizados experimentos e análise microbiológica utilizando o método SODIS com e sem o uso de concentrador solar. Com isso pôde-se observar que a desinfecção utilizando o 
concentrador solar atendeu às expectativas, eliminando completamente Coliformes totais e termotolerantes reduzindo em 2 horas o tempo de exposição solar, sendo mais eficiente que o teste realizado sem o uso do concentrador solar. Este, por sua vez, reduziu a concentração microbiana do sistema, mas não eliminou totalmente a presença de Coliformes totais e termotolerantes, contidos nas amostras.

Comparando os resultados com a legislação vigente, que dispõe sobre o padrão de potabilidade da água, o ideal é proceder com a desinfecção utilizando o concentrador de raios solares, pois este elimina completamente micro-organismos indicadores de contaminação fecal.

O método SODIS é viável para ser implementado em áreas que não sejam atendidas pelo sistema de abastecimento público e registrem altas temperaturas, características presentes nas comunidades rurais do semiárido paraibano.

\section{REFERÊNCIAS}

AESA - Agência Executiva de Gestão das Águas do Estado da Paraíba. Disponível em: < http://www.aesa.pb.gov.br/>. Acesso em: 18 de janeiro de 2014.

APHA, AWWA. WPCF. Standard Methtods for Examination of Water and Wastewater. 15ed. Washington, D.C American Public Health Association, American Water Works Pollution Control Federation, 1995.

BRASIL. MINISTÉRIO DA SAÚDE. Portaria 2.914 de Dezembro de 2011. Dispõe sobre procedimentos de controle e de vigilância da qualidade da água para consumo humano e seu padrão de potabilidade. Brasília: Ministério da Saúde, 2011.

CARRON, W.; GUIMARÃES, O.. As Faces da Física. 2 ed. São Paulo, SP: Editora Moderna, 2006.

MELÉNDEZ, G. S.. Desinfecção de efluente sanitário por radiação UV e gama: efeitos na inativação de Ovos de ascaris spp. Belo Horizonte - MG, 2011.

ONU - ORGANIZAÇÃO DAS NAÇÕES UNIDAS (2013). Disponível em:< http://www.onu.org.br/a-onu-em-acao/a-onu-em-acao/a-onu-e-a-agua/>. Acesso em: 18 de fevereiro de 2014.

PARTENIANI, J. E. S.; SILVA, M. J. M.. Uso de garrafas pet e energia solar na desinfecção de águas em comunidades rurais. Espírito Santo do Pinhal, 2005.

RODRIGUES, D. G.. Desinfecção da água por pasteurização solar (SOPAS) em comunidades rurais. Campinas - SP, 2011.

SILVA, M. J. M. da. Desinfecção de Água utilizando Energia Solar (SODIS): Inativação e Recrescimento Bacteriano. Campinas - SP, 2004.

SODIS (2013). Disponível em: < http://www.sodis.ch/index_EN>. Acesso em 14 de janeiro de 2014.

SOUZA, H. H. S.; PAULO, P. L.. Avaliação da Desinfecção Solar (SODIS) de água cinza. Campo Grande - MS, 2009.

WEGELIN, M., et al. Solar Water Disinfection: Scope on Process and Analysis of Radiation Experiments, Journal of Water Suply: Research and Technology - Aqua, 1994. 